\title{
Increase in summer European ozone amounts due to climate change
}

\author{
Frederik Meleux ${ }^{\mathrm{a}, *}$, Fabien Solmon $^{\mathrm{b}}$, Filippo Giorgi ${ }^{\mathrm{b}}$ \\ anstitut National de l'Environnement Industriel et des Risques, INERIS, Parc Technologique ALATA-B.P. No. 2, \\ 60550 Verneuil en Halatte, France \\ ${ }^{\mathrm{b}}$ Abdus Salam International Centre for Theoretical Physics, Italy
}

The local and regional distribution of pollutants is significantly influenced by weather patterns and variability along with the spatial patterns of emissions. Therefore, climatic changes which affect local meteorological conditions can alter air quality. We use the regional air quality model CHIMERE driven by meteorological fields from regional climate change simulations to investigate changes in summer ozone mixing ratios over Europe under increased greenhouse gas (GHG) forcing. Using three 30-year simulation periods, we find that daily peak ozone amounts as well as average ozone concentrations substantially increase during summer in future climate conditions. This is mostly due to higher temperatures and reduced cloudiness and precipitation over Europe and it leads to a higher number of ozone events exceeding information and warning thresholds. Our results show a pronounced regional variability, with the largest effects of climate change on ozone concentrations occurring over England, Belgium, Germany and France. The temperature-driven increase in biogenic emissions appears to enhance the ozone production and isoprene was identified as the most important chemical factor in the ozone sensitivity. We also find that summer ozone levels in future climate projections are similar to those found during the exceptionally warm and dry European summer of 2003. Our simulations suggest that in future climate conditions summer ozone might pose a much more serious threat to human health, agriculture and natural ecosystems in Europe, so that the effects of climate trends on pollutant amounts should be considered in future emission control measures.

Keywords: Ozone; Air quality; Climate changes; Modelling; Public information

\section{Introduction}

Significant adverse effects of tropospheric ozone on human health (Schlink et al., 2006; Parodi et al., 2005), agriculture (e.g. Chameides et al., 1999; Fuhrer and Booker, 2003) and natural ecosystems

\footnotetext{
*Corresponding author.

E-mail address: frederik.meleux@ineris.fr (F. Meleux).
}

(Scebba et al., 2005) are well known. Maximum ozone concentrations are reached over Europe mostly during the summer period because meteorological conditions (high temperatures, low precipitation, weak winds) allow enhancements of ozone precursor chemistry and ozone photochemical production efficiency (Guicherit and Dop, 1977; Sillman, 2000). In European countries a public information procedure applies when the near-surface 
ozone concentration exceeds $90 \mathrm{ppb}$. This procedure is issued from a European directive aimed at limiting the impacts of ozone on human health and protecting the population in areas affected by high ozone concentrations. For example in the Paris area this information threshold was exceeded on average 13 days per summer between 1995 and 2003.

Many climate change simulations indicate much warmer and drier summer conditions over Western Europe and the Mediterranean region in future decades of the 21st century (Giorgi and Bi, 2005), which can potentially yield an increase in summer background ozone concentrations (Langner et al., 2005). In fact, the trends in European summer climate observed in recent decades are remarkably similar to the changes simulated in model projections for the 21 st century (Pal et al., 2004). In particular, studies indicate that the climate patterns that lead to the exceptionally hot and dry European summer of 2003 might occur much more frequently in future conditions with increasing GHG concentrations (Schar et al., 2004; Pal et al., 2004; Meehl and Tebaldi, 2004). Near-surface ozone during the 2003 summer was exceptionally high (Vautard et al., 2005) and this might have contributed to the dramatic rate of mortality noticed during that summer (Stedman, 2005). In fact, Langner et al. (2005) and Szopa et al. (2006) found marked increases of near-surface summer ozone concentrations in response to climate change and assuming no emission control measures. These were attributed to much warmer and drier European summers under future climate conditions. Mixed results were found for the changes in sulphur and nitrogen deposition.

Other studies of the effects of climate change on regional air pollution are those of Hogrefe et al. (2004) and Knowlton et al. (2004), who focused on regions within the continental United States (US). They used a regional air quality model driven offline by meteorological fields from regional climate model simulations (nested in corresponding global model simulations) to investigate possible future changes in summer near-surface ozone concentrations over the eastern US and the New York metropolitan region, respectively. Simulations were performed for different IPCC emission scenarios and future time periods. They found an increase in ozone concentration due to climate change alone primarily tied to an increase in biogenic emissions due to higher temperatures. More importantly, however, they estimated that this increase is substantial compared to changes in anthropogenic precursor emissions and therefore that climate change is an important aspect to be considered in future air quality policy planning. Similar results were found in the regional model-based studies of Steiner et al. (2006) (for California) and Dawson et al. (2007) (for the eastern US), although the importance of the climate forcing on the ozone concentrations varied in different sub-areas of the regions considered.

Because of these findings, it is reasonable to hypothesize that summer tropospheric ozone might become an increasing threat to human health, agriculture and ecosystems over Europe in warmer climate conditions. In this paper we explore this issue by using regional scale climate and air quality models to simulate future European ozone levels for the latest decades of the 21 st century under two GHG emission scenarios of the Intergovernmental Panel on Climate Change (IPCC). Compared to previous studies we use here a much larger set of simulations (30 summers for each of a present day and two future scenario simulations), which allows us to obtain more robust signals and to address issues of inter-annual variability of the results.

\section{Models and experiment design}

We use an air quality model for Europe driven off-line by meteorological fields from regional climate model simulations. The regional climate simulations were performed using the model RegCM as described by Giorgi et al. (2004a, b) (hereafter referred to as GBP04a,b). This regional climate modelling system has been used for over a decade in a wide variety of applications (e.g. Giorgi and Mearns, 1999; Giorgi et al., 2006), including long term simulations over different regions of the world (e.g. Giorgi et al., 1993a, b; Small et al., 1999; Sun et al., 1999; Im et al., 2006; Seth and Rojas, 2003; Francisco et al., 2006), paleoclimate simulations (Hostetler et al., 1994), climate change simulations (Giorgi et al., 1992, 1998; Hirakuchi and Giorgi, 1995; Diffenbaugh et al., 2005; Gao et al., 2006) and chemistry-climate interactions (Giorgi et al., 2002, 2003). The model domain encompasses the entire European region and adjacent ocean waters at $50 \mathrm{~km}$ grid spacing and 18 vertical sigma levels, 6 of which lie in the planetary boundary layer (see GPB04a).

The air quality model is a state-of-the-art chemistry-transport model (CTM) named CHIMERE 
and is documented in several articles (e.g. Schmidt et al., 2001; Bessagnet et al., 2004). In addition, a description of recent developments of CHIMERE can be found in the web site http://euler.lmd. polytechnique.fr/chimere. For this study, CHIMERE covers a large part of Europe with a $0.5^{\circ} \times 0.5^{\circ}$ horizontal resolution. Its vertical grid consists of 8 stretched levels from the surface up to $500 \mathrm{hPa}$. The top of the first layer is approximately $45 \mathrm{~m}$ above the surface, and 6 layers allow to describe the chemical processes in the daytime boundary layer. This model is used in several European countries for operational air quality forecasting and atmospheric pollutant dispersion studies.

The experiment design is as follows. GBP04a, b simulated three 30-year periods: 1961-1990 for present day conditions and 2071-2100 for future conditions under the $\mathrm{A} 2$ and $\mathrm{B} 2$ IPCC emission scenarios (see GBP04a, b). The A2 lies towards the upper end of the IPCC emission scenario range, with a $\mathrm{CO}_{2}$ concentration reaching about $850 \mathrm{ppm}$ by 2100 , while the $\mathrm{B} 2$ lies towards the low end of the range, with a $\mathrm{CO}_{2}$ concentration of about $550 \mathrm{ppm}$ by 2100 . The RegCM simulations are driven at the lateral boundaries by meteorological fields obtained from corresponding simulations with the Hadley Centre global model HadAM3 H (see GBP04a, b). Out of the 30 year simulations, 6-hourly meteorological fields are extracted for all (90) summers (June-July-August-September). These are passed to CHIMERE, after horizontal and vertical bilinear interpolation onto the CHIMERE grid, as meteorological input needed to simulate the air quality for the 90 summers (30 for present day and 30 for A2 and B2, respectively). Note that 6-hourly fields provide an adequate description of the evolution of synoptic events. CHIMERE also needs as input some surface related variables, such as surface and ground temperature and planetary boundary layer (PBL) height. These are provided by the RegCM at 3 hourly intervals in order to better describe the diurnal cycle. The PBL height is then used by CHIMERE to calculate vertical dispersal of tracers. A description of the model PBL scheme and simulations is given by Giorgi et al. (2003).

Anthropogenic emissions of chemical compounds are taken from the EMEP database for the year 2002 (Vestreng, 2003). The chemical initial and lateral boundary conditions are provided from monthly climatologies for the year 2002 obtained with the second generation MOZART global CTM
(Horowitz et al., 2003). Anthropogenic emissions and initial/boundary chemical conditions are the same for the present day and the scenario simulations, which allows us to isolate the effects of climate change conditions.

Biogenic emissions of isoprene and terpenes (affected by alpha-pinene in the chemical mechanism) are parameterised as fluxes $\mathrm{F}_{i}=\varepsilon_{i} \mathrm{D} \gamma_{i}$ (Günther, 1997), with $\varepsilon_{i}$ being the species dependent "emission potential" and D the "foliar density". The values of $\varepsilon_{i}$ and $\mathrm{D}$ are taken from Simpson (1999). The "environmental correction factor" $\gamma_{i}$ accounts for the dependence on temperature and insolation (e.g. Günther, 1997). The spatial distribution of tree species is established following the methodology outlined in Simpson (1999). Therefore the SEI (Stockholm Environment Institute) land cover database, which details the fraction of different tree species over Europe, is interpolated on the CHIMERE grid. The 136 SEI land use classes are aggregated into 11 "emitter" classes. Oaks, for example are differentiated in the classes highly isoprene emitting, highly terpene emitting and low biogenic VOC emitting oaks. As this attribution of classes is sometimes ambiguous, national tree species inventories from Simpson (1999) are used to verify the fraction of each emitter class on a countrywide level and to adjust it, when necessary. The isoprene and monoterpenes contents, which are the main biogenics species emitted, are sensitive to the emission potentials used to compute emissions as well as to the chemical reactions taken into account in the chemical scheme (von Kuhlmann et al., 2004; Moukhtar et al., 2005).

Biogenic VOC emissions are the only emissions that depend on climate conditions, and more specifically temperature, in our simulations and consequently they are the only emissions to vary between reference and future climate simulations. Therefore, we estimate the effect of climate change on ozone concentrations without considering possible anthropogenic pollutant emission changes or any feedbacks from the chemical compounds to the meteorological fields, but allowing changes in natural biogenic emissions. Stratospheric ozone, which may impact ozone levels in the boundary layer (Isaksen et al., 2005), is not considered as well.

GBP04a, b describe the regional climate experiments in detail, focusing on the simulated mean climatology and inter-annual variability. The present day simulation is generally of good quality, with summer temperature biases mostly lower than 
a

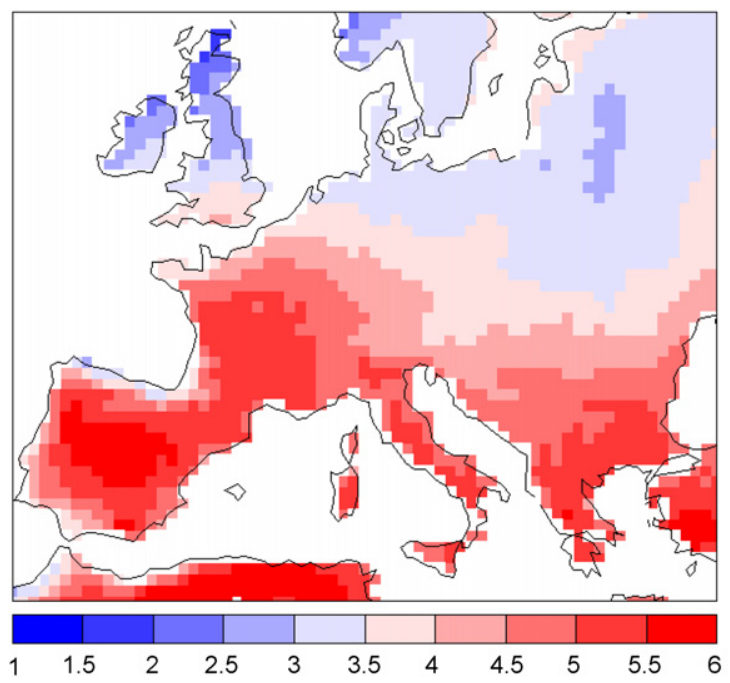

b

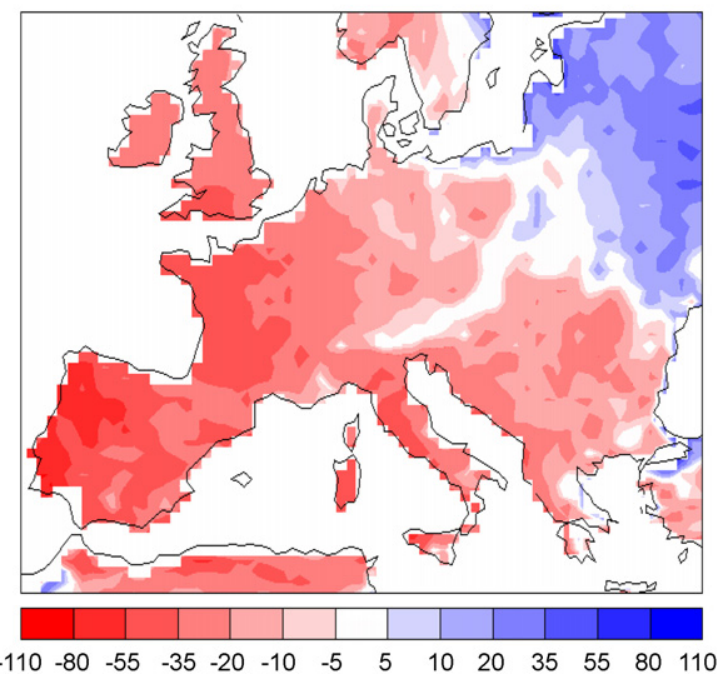

Fig. 1. Difference between B2 (2071-2100) and present day (1961-1990) for average summer temperature (Kelvin, 1a) and average precipitation $(\mathrm{mm} /$ day, $1 \mathrm{~b})$.

$1-2 \mathrm{~K}$ and summer precipitation biases mostly lower than $25 \%$. Inter-annual variability is slightly overestimated in the reference simulation. In future climate conditions the model simulates a substantial summer warming of $3-5{ }^{\circ} \mathrm{C}$ over Europe and the Mediterranean region (greater by $1-2^{\circ} \mathrm{C}$ in the $\mathrm{A} 2$ than the B2 experiment) along with a widespread decrease of precipitation of up to $30-40 \%$ (both in the $\mathrm{A} 2$ and $\mathrm{B} 2$ runs). The spatial patterns of these changes are illustrated in Fig. 1, which shows the projected differences of temperature and precipitation over Europe between the B2 and reference simulations of GBP04a,b (the changes for the A2 scenario show similar patterns). In addition, inter-annual variability increases in the scenario simulations compared to present day for both temperature and precipitation and summer cloudiness decreases (GBP04a,b). Also note that the RegCM has been previously shown to provide a realistic representation of synoptic events over the European region (Giorgi et al., 1990; Giorgi and Marinucci, 1991). The reader is referred to GBP04 for more details on the climate simulations used to drive CHIMERE.

\section{Results}

It is beyond the purpose of this paper to present a thorough validation of the full chemical simulations provided by the RegCM-driven CHIMERE model. However, Fig. 2 presents an assessment of the simulated ozone amounts. Air quality measurements before 1990 are not sufficient to evaluate the model behaviour, therefore we compare average simulated summer ozone for the period 1980-1990 (the last decade of the present day run) with a set of ozone mixing ratio available for 1990-2003 from the European EMEP database. This comparison is carried out on a country-by-country basis and a special focus is given to the countries located around the centre of the domain, where at least 2 stations are available for this period. In all, a set of 89 stations was used in this analysis. They are representative of the background ozone behaviour according to the EMEP recommendations for positioning the measurement sites to assess longrange transport. In the comparison we focus on statistics related to ozone impacts, such as the daily peak ozone mixing ratio.

The simulated average daily peak ozone concentrations for the summer months (June-September, Fig. 2a) over the selected stations show a good agreement with the EMEP values, with differences between observed and simulated values being mostly within the model inter-annual variability. The simulated number of days of ozone concentration exceeding the information threshold (Fig. 2b) is also in line with the observed values. These figures indicate that CHIMERE driven by meteorological fields from the RegCM is capable of simulating realistic European ozone amounts, and that the model results are representative of the present day ozone levels even if 

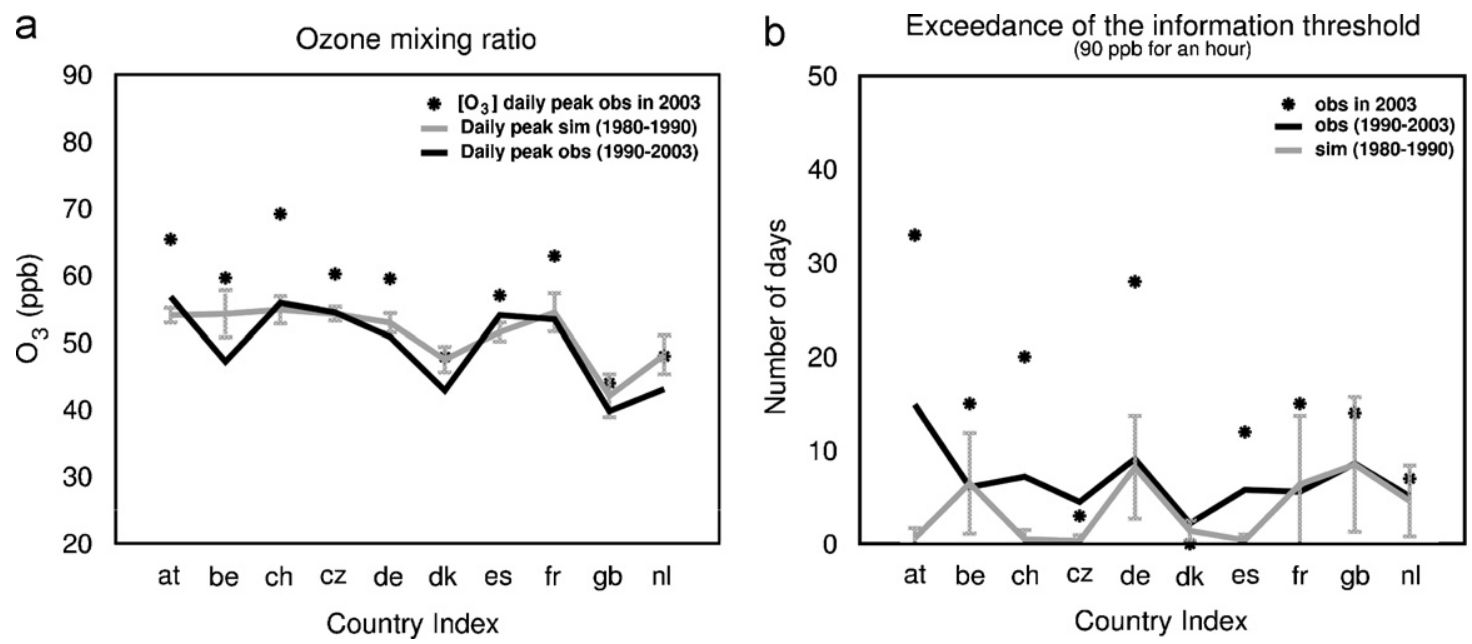

Fig. 2. Country-by-country comparison of averaged daily peak ozone mixing ratio (2a) and of number of days per year with ozone exceeding the information threshold (2b) computed for the present day period 1980-1990 and observations over the EMEP stations (at least 2 stations per country) for 1990-2003. At is Austria, be is Belgium, ch is Switzerland, cz is Czech Republic, de is Germany, dk is Denmark, es is Spain, fr is France, gb is UK, $\mathrm{nl}$ is Netherlands. Also shown (asterisks) are the values for the summer of 2003, and vertical bars represent the inter-annual variability as measured by the standard deviation.

emission policies during the last decades led to small changes in ozone concentration over 10 -year periods (Jonson et al., 2006; Vautard et al., 2006). Therefore, this comparison shows that the RegCM-driven CHIMERE can be applied to study future ozone concentrations with some degree of confidence. Also shown in Figs. 2a, b are the high observed ozone amounts for the summer of 2003, which are well outside the ozone inter-annual variability (Schar et al., 2004). In a previous study, Vautard et al. (2005) used the CHIMERE model to analyse the exceptional ozone levels caused by the heat wave that occurred during that summer and found that the model successfully captured this extreme episode.

Fig. 3 presents the difference between A2 and present day simulated values of near surface daily peak ozone (PO, Fig. 3a) and daily averaged ozone (AO, Fig. 3c) mixing ratios. The values are calculated by averaging the respective simulations over all 30 summers. The PO is a relevant quantity to assess human health risks, since human health can be strongly affected by exposure to high ozone amounts. The AO is more relevant for effects on agriculture and ecosystems, which are sensitive to chronic exposure. Differences between A2 and B2 $\mathrm{PO}$ are shown in Fig. 3b.

In the A2 simulation, both the $\mathrm{PO}$ and $\mathrm{AO}$ increase substantially throughout Europe compared to present day. The PO increases by up to $25 \%$ (16-18 ppb), with a maximum increase over the western part of Europe, especially north-eastern France, central-western Germany and Belgium. Large increases are also found over southern England and in the Jura mountain region. The other European regions exhibit a lower PO increase, but still up to 5-10\% (e.g. in northern Italy and Spain). A similar increase is found for the B2 simulation (Fig. 3b), but with lower magnitudes. The largest differences between the A2 and B2 PO appear over the north-western portions of the domain.

The maximum increase in AO (Fig. 3c) occurs over eastern France and western Germany, with AO changes ranging between 7 and $10 \mathrm{ppb}(+10-16 \%)$. The marine boundary layer also shows two areas with large increases. One occurs over the Atlantic Ocean and is due to ozone accumulation induced by a north-east anticyclonic flow (Pal et al., 2004). Another well-known highly polluted marine area which shows a large ozone increase is the Mediterranean Sea around Marseille, which is mainly caused by high anthropogenic and natural emissions in this area (Dufour et al., 2005) coupled with low dispersive conditions (Kalthoff et al., 2005). The RegCM tends to produce rather stable boundary layers over ocean (Giorgi et al., 1993a,b), which may also contribute to the relatively large changes found over the Mediterranean. Differences between the A2 and B2 AO (Fig. 3d) show patterns similar to those of Fig. 3b, with larger increase over the Atlantic Ocean than over land. 
a

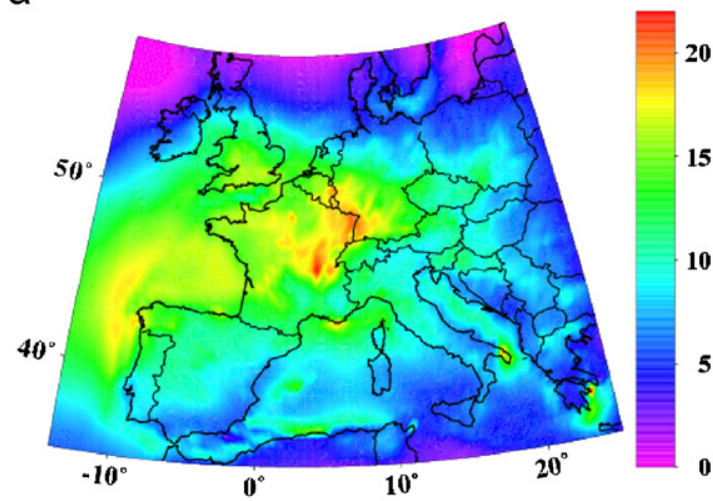

C

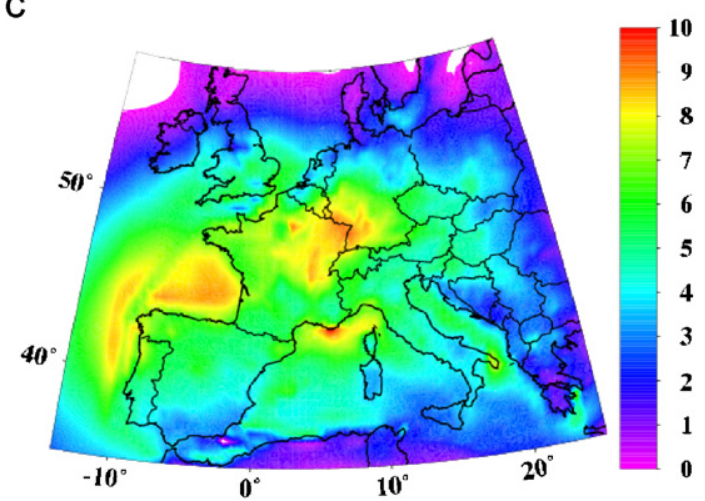

b

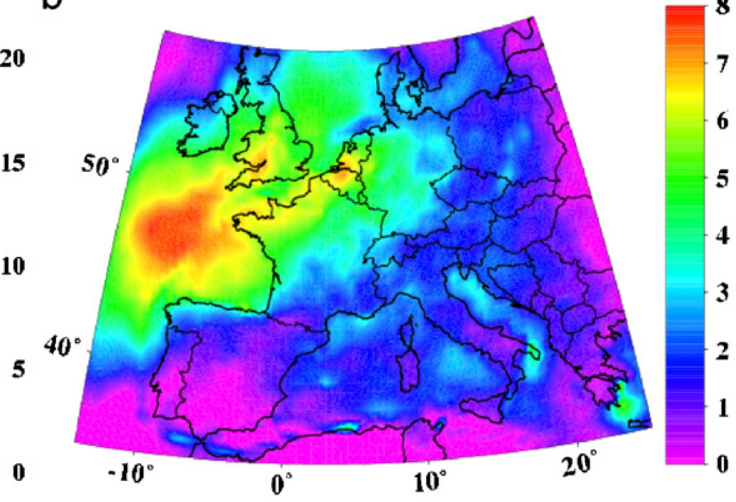

d

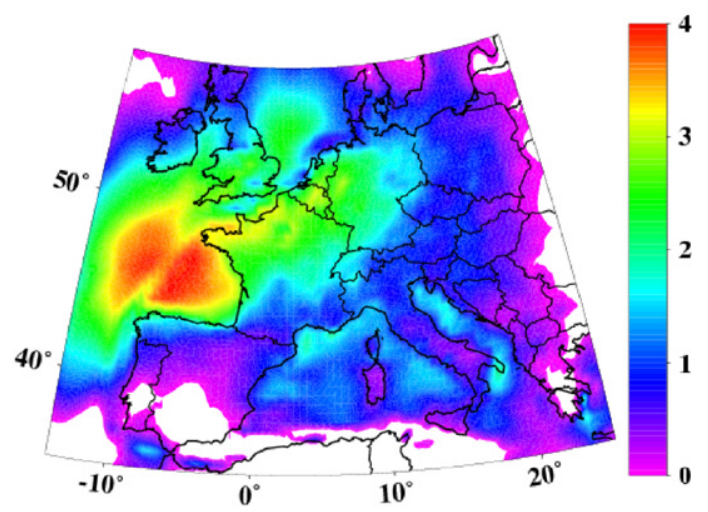

Fig. 3. Difference in average peak daily near-surface ozone mixing ratio (ppb) between A2 and present day ( $3 a$ ) and between A2 and B2 (3b); difference in average ozone mixing ratio (ppb) between A2 and present day (3c) and between A2 and B2 (3d).

The general increase in ozone we found under A2/B2 forcing is due to a multiplicity of climate factors, such as increased temperature, decreased wet removal associated with the decrease of summer precipitation, increased photolysis of primary and secondary pollutants due to lower cloudiness (see GBP04a, b) and increased biogenic emissions due to higher temperatures (Stevenson et al., 2005). We analysed the contribution of different factors by comparing their changes with the changes in ozone concentration, both in terms of average changes and pattern correlation (Table 1). The calculations have been carried out in two ways, one over land, and one for the whole domain. In interpreting the results of Table 1, we stress that many of these factors are interconnected, and therefore it is difficult to unambiguously determine which one is dominant.

With these provisions, Table 1 shows that the scenario conditions with higher temperatures and reduced cloudiness drive a more effective photochemical activity which could explain for instance the several ppb increase simulated for formaldehyde and carbon monoxide over a large portion of
Europe. These are two chemical species resulting from the oxidation of hydrocarbons. As the anthropogenic emissions are kept the same for all runs, it is likely that the chemical activity is responsible for these changes. The future combination of less dispersive conditions and lower removal efficiency (increased sea level pressure and subsidence, see GBP04a, b) leads to increased concentrations of pollutants in the boundary layer, and in particular an increase in NOx availability (up to $9 \%$ more in A2 than in REF) for ozone production. One important result is that the increases in ozone are highly correlated with isoprene concentration changes. This very reactive species (Liakakou et al., 2007) increases by a factor of up to 2 compared to the present day mean. It is therefore important to highlight the co-increase in both ozone precursors, as the ozone formation is dependent on the NOx/ VOC ratio. We must also remember that the high biogenic reactivity sustains the ozone production cycle and increases the $\mathrm{O}_{3}$ yield per NOx molecule. Often, away from anthropogenic emission areas, the ozone production is NOx dependent. Therefore, in 
Table 1

Simulated A2 and B2 minus present day (REF) changes in different factors affecting the ozone concentration and spatial linear correlation between these changes and the change in average ozone concentration

\begin{tabular}{|c|c|c|c|c|}
\hline & \multicolumn{2}{|l|}{ A2-REF } & \multicolumn{2}{|l|}{ B2-REF } \\
\hline & Mean $(\%)$ & $\mathrm{O}_{3}$ corr. & Mean $(\%)$ & $\mathrm{O}_{3}$ corr. \\
\hline Isoprene & $97.2(>1000)$ & $0.9(0.1)$ & $67.9(65.5)$ & $0.9(0.6)$ \\
\hline Carbon monoxide & $2.5(2.6)$ & $0.8(0.9)$ & $2.0(1.9)$ & $0.9(0.8)$ \\
\hline Methane & $0.0(0.0)$ & $-0.5(-0.6)$ & $0.0(0.0)$ & $-0.5(-0.3)$ \\
\hline Formaldehyde & $59.0(49.3)$ & $0.9(0.8)$ & $42.4(34.4)$ & $0.9(0.9)$ \\
\hline Nitric acid & $7.7(14.4)$ & $0.7(0.7)$ & $4.9(7.5)$ & $0.7(0.7)$ \\
\hline PAN & $1.1(2.3)$ & $0.3(0.4)$ & $2.4(1.9)$ & $0.5(0.4)$ \\
\hline NOx & $7.6(8.9)$ & $0.5(0.6)$ & $5.1(4.6)$ & $0.6(0.5)$ \\
\hline $\mathrm{O}_{3}$ Vdep & $-3.7(-6.2)$ & $-0.3(-0.4)$ & $-2.2(-2.0)$ & $-0.4(-0.3)$ \\
\hline PBL Hght & $1.4(-4.0)$ & $0.0(-0.3)$ & $1.9(-1.0)$ & $0.2(-0.2)$ \\
\hline Horizontal wind & $-1.3(-2.0)$ & $-0.3(-0.2)$ & $-0.4(-0.8)$ & $-0.2(-0.1)$ \\
\hline Temperature & $1.5(1.4)$ & $0.9(0.8)$ & $1.0(0.9)$ & $0.9(0.8)$ \\
\hline Attenuation factor & $5.2(5.0)$ & $0.9(0.8)$ & $4.0(3.8)$ & $0.8(0.8)$ \\
\hline Humidity & $15.7(16.8)$ & $0.8(0.8)$ & $9.8(10.7)$ & $0.8(0.7)$ \\
\hline
\end{tabular}

The calculations are conducted for a selected portion of the domain where isoprene concentration exceed 0.1 ppb in the present day simulation, approximately $2 / 3$ of the total number of grid points (almost all land grid points), and the whole domain between brackets. Changes are expressed as percent of present day simulated values.

these regions of the domain an increase in NOx concentrations implies an increase in ozone production. Overall, our simulations suggest that the enhanced chemical activity is mainly driven by the warming-induced increase in biogenic emissions, as indicated by a high correlation between isoprene concentration changes and ozone concentration changes. The climate factor which mostly affects the increase in ozone concentration is thus the warming, which induces a strong increase in biogenic emissions.

In addition, the photolysis rates are higher in the scenario runs than in the present conditions due to a decrease in cloud cover over Europe during the summer season (see GBP04b). This effect is illustrated by an increase of the attenuation coefficient (Table1) which describes the dependency of the photolysis rates on cloud cover (a maximum value of 1 indicates clear sky conditions). An increase in photolysis rates in connection with an increase in humidity, leads to a greater production of hydroxyl radicals, the main short-lived species involved in the ozone-producing chemical mechanism. This does not necessarily imply higher $\mathrm{O}_{3}$ concentrations, but an alteration of the ozone production cycle(Dawson et al., 2007). When analysing the processes involved in ozone formation, it is evident that $\mathrm{OH}$ does not just oxidise VOC compounds but also allows the conversion of $\mathrm{NO}$ to $\mathrm{NO}_{2}$, thereby leading to ozone formation. $\mathrm{OH}$ can also react with $\mathrm{NO}_{2}$ leading to $\mathrm{HNO}_{3}$ (increase by $7.7 \%$, Table 1 ), a sink for the ozone cycle production. Another effect of $\mathrm{OH}$ formation is that it could "steal" $\mathrm{O}\left({ }^{1} \mathrm{D}\right)$ from the ozone chemical production cycle.

Table 1 also indicates that PAN concentrations increase over the northern part of the domain, both over sea and land. The PAN chemistry is very temperature dependent and induces a NOx transport for long distances, providing ozone precursors after self-decomposition over remote areas, and hence promoting ozone formation. In our scenario simulations PAN increases in the remote Atlantic boundary layer by up to $50 \%$ in A2 ( $0.3 \mathrm{ppb}$ more than in REF), but no clear relationships were found to diagnose a possible contribution from PAN chemistry in the increase of ozone production.

Climatic factors other than warming and decreased cloudiness show less pronounced impact on ozone changes. The decrease of ozone removal as well as the decrease of the horizontal transport appear to have a relatively low impact on ozone, even if they can be expected to amplify the ozone accumulation in the boundary layer (in agreement with a negative correlation of -0.3 ). Finally, the last two climate factors we analysed, boundary layer thickness and horizontal wind component, did not have a direct significant influence on ozone despite their expected effects on pollutant dilution (see Table 1). 

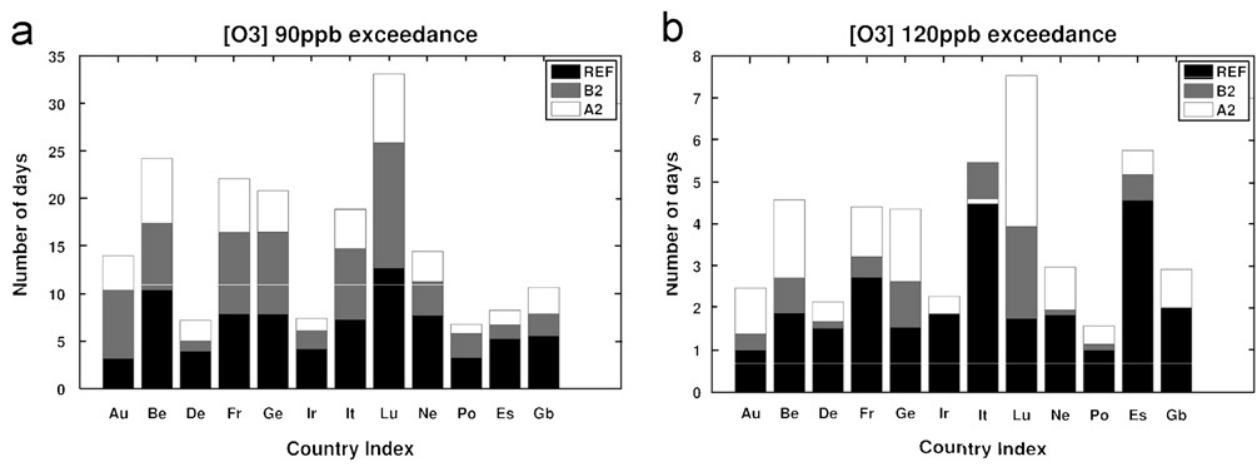

Fig. 4. Average number of days exceeding the ozone information (4a) and the ozone warming (4b) thresholds per summer over 12 European countries. The averages are calculated using all 30 summers of each simulation. Black is for the present day run, gray is for the B2 run and white is for the A2 run. Countries are, from left to right, Austria, Belgium, Denmark, France, Germany, Ireland, Italy, Luxembourg, Netherlands, Portugal, Spain and UK.

As mentioned, an important measure of the ozone threat to human health is the exceedance of ozone mixing ratio above the 90 and $120 \mathrm{ppb}$ thresholds. When ozone is forecast to exceed the $90 \mathrm{ppb}$ threshold for at least $1 \mathrm{~h}$, under European regulation the population needs to be informed. When the $120 \mathrm{ppb}$ threshold is exceeded, a health warning is issued and local policymakers have to adopt measures to reduce emissions. Figs. $4 a$ and $b$ show the average number of days per summer with ozone exceeding the 90 and $120 \mathrm{ppb}$ thresholds, respectively, in the reference, A2 and B2 simulations. The number is calculated for all grid points included in 12 European countries.

A number of features are shown by Figs. 4a and b. First, the number of exceedance days increases substantially in both scenario simulations compared to the present day case, and it is higher for the A2 scenario than for the $\mathrm{B} 2$ one for most of the countries. For the $90 \mathrm{ppb}$ threshold the number of exceedance days more than doubles in the A2 scenario compared to present day over most countries considered. The countries with the largest increase in exceedance days above the $90 \mathrm{ppb}$ threshold are Austria, Belgium, France, Germany, Italy, Luxembourg and the Netherlands. Spain and Italy have a large number of days with ozone exceeding the $120 \mathrm{ppb}$ threshold in the present day run and only modest increases in the scenario runs. Conversely, large increases in days with ozone exceeding the $120 \mathrm{ppb}$ threshold occur over Belgium, France, Germany and Luxembourg. In addition, we find an increase in the duration of high ozone level episodes for the A2 scenario compared to the present day case (Fig. 5). There-

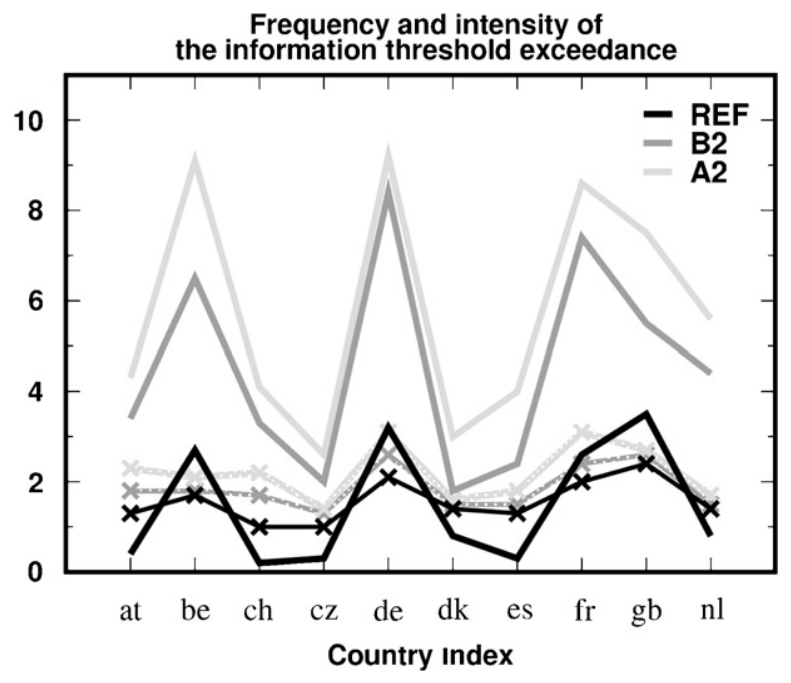

Fig. 5. Mean number of episode with ozone information threshold exceedances per summer for each country (solid lines) and the associated mean duration in days (crosses) of these high ozone episodes.

fore, our simulation indicates that climate change might lead to more frequent and persistent high ozone episodes. Results for the B2 scenario exhibit patterns similar to those for the A2 one but of smaller magnitude.

Fig. 6 compares the average number of days with ozone exceeding the information threshold $(90 \mathrm{ppb})$ in the $\mathrm{A} 2$ and $\mathrm{B} 2$ simulations with the same number for the summer of 2003 obtained from the EMEP station dataset. It shows that the number of high ozone events in 2003 is closer to that of the future climate simulation than the present day conditions (Fig. 2). The vertical bars depict the inter-annual 


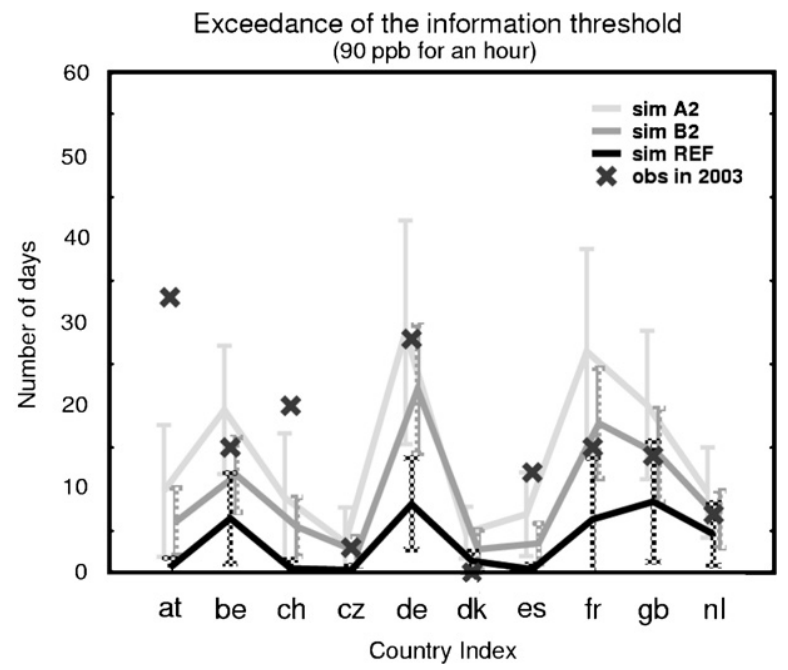

Fig. 6. Average number of days per summer with ozone concentrations exceeding the information threshold $(90 \mathrm{ppb})$ for the A2 and B2 simulations and for the 2003 EMEP observations over the central European countries of Fig. 2. The vertical bars indicate the interannual variability (standard deviation) for the 30 years simulations.

variability of simulated exceedance days and shows that the 2003 summer is almost always within the A 2 and B2 model results. Since, as mentioned, it has been suggested that summers such as that of 2003 may occur much more frequently in the future (Schar et al., 2004; Pal et al., 2004; Meehl and Tebaldi, 2004), our simulations indicate that the resulting very poor air quality conditions which occurred in the 2003 summer might also become more frequent under climate change conditions unless effective emission reduction measures counterbalance the effect of climate trends on ozone amounts. We also note from Fig. 6 a general increase of ozone inter-annual variability in the scenario runs compared to the reference ones. This is evidently associated with the increase in interannual variability of temperature and precipitation found by GBP04a, b.

\section{Conclusions}

Our simulations show that ozone increases under projected changes in summer European climate and can potentially pose an increasingly serious threat to human health and the environment in Europe, especially over western and central Europe. This is mostly because of the large increase in temperature and decrease in cloudiness projected for summer European climate, which leads to higher photo- chemical production of ozone from biogenic species. Although our results are from individual simulations, the climate change conditions used in this study (GBP04a, b) are in line with those projected by most other global (Giorgi and $\mathrm{Bi}, 2005$ ) and regional (Deque et al., 2005) climate models. We thus assess that our findings are robust. This robustness is further strengthened by the similarities we find between our future air quality simulations and the exceptional (and devastating) conditions found during the summer of 2003, which many believe will be much more frequent under increased GHG forcing (Schar et al., 2004; Pal et al., 2004; Meehl and Tebaldi, 2004).

In our simulations we used the same emissions and chemical boundary conditions for the present day and future periods, thereby isolating the effect of climate change (Jonson et al., 2006). It is likely that emissions of ozone precursors will decrease in the future, but this change will probably vary from country to country, leading to issues of transboundary pollution transport (Szopa et al., 2006). With these caveats in mind, the impact of climate change on air quality found in this article calls for the need to carefully consider the effects of climate change on air quality to develop effective future emission control policies.

\section{Acknowledgements}

The authors acknowledge EMEP for providing the anthropogenic emissions. We also thank Bertrand Bessagnet for his helpful advices.

\section{References}

Bessagnet, B., Hodzic, A., Vautard, R., Beekmann, M., Cheinet, S., Honoré, C., Liousse, C., Rouil, L., 2004. Aerosol modeling with CHIMERE - preliminary evaluation at the continental scale. Atmospheric Environment 38 (18), 2803-2817.

Chameides, W.L., Xingsheng, L., Xiaoyan, T., Xiuji, Z., Chao, L., Kiang, C.S., St. John, J., Saylor, R.D., Liu, S.C., Lam, K.S., Wang, T., Giorgi, F., 1999. Is ozone pollution affecting crop yields in China? Geophysical Research Letters 26 (7), 867-870.

Dawson, J.P., Adams, P.J., Pandis, S.N., 2007. Sensitivity of ozone to summertime climate in the eastern USA: a modeling case study. Atmospheric Environment 41, 1494-1511.

Deque, M., Jones, R.G., Wild, M., Giorgi, F., Christensen, J.H., Hassell, D.C., Vidale, P.L., Rockel, B., Jacob, D., Kjellstrom, E., de Castro, M., Kucharski, F., van den Hurk, B., 2005. Global high resolution versus limited area model climate change scenarios over Europe: quantifying confidence levels from PRUDENCE results. Climate Dynamics 25, 653-670. 
Diffenbaugh, N.S., Pal, J.S., Trapp, R.J., Giorgi, F., 2005. Finescale processes regulate the response of extreme events to global climate change. In: Proceedings of the National Academy of Sciences of the United States of America, vol. 102, pp. 15774-15778.

Dufour, A., Amodei, M., Ancellet, G., Peuch, V.-H., 2005. Observed and modelled "chemical weather" during ESCOMPTE. Atmospheric Research 74 (1-4), 161-189.

Francisco, R.V., et al., 2006. Regional model simulation of summer rainfall over the Philippines. Theoretical Applied Climatology 86, 215-227.

Fuhrer, J., Booker, F., 2003. Ecological issues related to ozone: agricultural issues. Environment International 29 (2-3), $141-154$

Gao, X., Pal, J.S., Giorgi, F., 2006. Projected changes in mean and extreme precipitation over the Mediterranean region from high resolution double nested RCM simulations. Geophysical Research Letters 33, L03706.

Giorgi, F., Marinucci, M.R., 1991. Validation of a regional atmospheric model over Europe: sensitivity of wintertime and summertime simulations to selected physics parameterizaions and lower boundary conditions. Quarterly Journal Royal Meteorology Society 117, 1171-1207.

Giorgi, F., Mearns, L.O., 1999. Introduction to special section: regional climate modelling revisited. Journal of Geophysical Research 104, 6335-6352.

Giorgi, F., Bi, X., 2005. Updated regional precipitation and temperature changes for the 21 st century from ensembles of recent AOGCM simulations. Geophysical Research Letters 32, L21715.

Giorgi, F., Marinucci, M.R., Visconti, G., 1990. Use of a limited area model nested in a general circulation model for regional climate simulation over Europe. Journal of Geophysical Research 95, 18413-18431.

Giorgi, F., Marinucci, M.R., Visconti, G., 1992. A 2XCO2 climate change scenario over Europe generated using a limited area model nested in a general circulation model, II: climate change scnario. Journal of Geophysical Research 97, 10028-19911.

Giorgi, F., Bates, G.T., Nieman, S.J., 1993a. The multi-year surface climatology of a regional atmospheric model over the western United States. Journal of Climate 6, 75-95.

Giorgi, F., Marinucci, M.R., Bates, G.T., DeCanio, G., 1993 b. Development of a second generation regional climate model (RegCM2). Part I: boundary layer and radiative transfer processes. Monthly Weather Review 121, 2794-2813.

Giorgi, F., Mearns, L.O., Shields, C., McDaniel, L., 1998. Regional nested model simulations of present day and 2XCO2 climate over the Central Plains of the U.S. Climatic Change 40, 457-493.

Giorgi, F., Bi, X., Qian, Y., 2002. Direct radiative forcing and regional climatic effects of anthropogenic aerosols over East Asia. A regional coupled climate-chemistry/aerosol model study. Journal of Geophysical Research 107, 4439.

Giorgi, F., Bi, X., Qian, Y., 2003. Indirect vs. direct effects of anthropogenic sulfate on the climate of East Asia as simulated with a regional coupled climate-chemistry/aerosol model. Climatic Change 58, 345-376.

Giorgi, F., X, Bi., Pal, J., 2004a. Mean, interannual variability and trends in a regional climate change experiment over Europe. II: present day climate (1960-1990). Climate Dynamics 22, 733-756.
Giorgi, F., Bi, X., Pal, J., 2004b. Mean, interannual variability and trends in a regional climate change experiment over Europe. I: climate change scenarios (2071-2100). Climate Dynamics 23, 839-858.

Giorgi, F., et al., 2006. Introduction to the TAC special issue: the RegCNET network. theoretical Applied Climatology 86, 1-4.

Guicherit, R., van Dop, H., 1977. Photochemical production of ozone in Western Europe (1971-1975) and its relation to meteorology. Atmospheric Environment 11 (2), 145-155.

Günther, A., 1997. Seasonal and spatial variations in the natural volatile organic compound, emissions. Ecology Application 7, $34-45$.

Hirakuchi, H., Giorgi, F., 1995. Multi year present day and 2XCO2 simulations of monsoon-dominated climate over Eastern Asia and Japan with a regional climate model nested in a general circulation model. Journal of Geophysical Research 100, 21,105-21,126.

Hogrefe, C., Lynn, B., Civerolo, K., Ku, J.-Y., Rosenthal, J., Rosenzweig, C., Goldberg, R., Gaffin, S., Knowlton, K., Kinney, P.L., 2004. Simulating changes in regional air pollution over the eastern United States due to changes in global and regional climate and emissions. Journal of Geophysical Research 109, D22301.

Horowitz, L.W., Walters, S., Mauzerall, D.L., Emmons, L.K., Rasch, P.J., Granier, C., Tie, X., Lamarque, J.-F., Schultz, M.G., Tyndall, G.S., Orlando, J.J., Brasseur, G.P., 2003. A global simulation of tropospheric ozone and related tracers: description and evaluation of MOZART, version 2. Journal of Geophysical Research 108 (D24), 4784.

Hostetler, S.W., Giorgi, F., Bates, G.T., Bartlein, P.J., 1994. The role of lake-atmosphere feedbacks in sustaining paleolakes Bonneville and Lahontan 18,000 years ago. Science 263, 665-668.

Im, E.-S., Park, E.-H., Kwon, W.-T., Giorgi, F., 2006. Present climate simulation over Korea with a regional climate model using a one-way double-nested system. Theoretical Applied Climatology 86, 187-200.

Isaksen, I.S.A., Zerefos, C., Kourtidis, K., Meleti, C., Dalsøren, S.B., Sundet, J.K., Grini, A., Zanis, P., Balis, D., 2005. Tropospheric ozone changes at unpolluted and semipolluted regions induced by stratospheric ozone changes. Journal of Geophysical Research 110, D02302.

Jonson, J.E., Simpson, D., Fagerli, H., Solberg, S., 2006. Can we explain the trends in European ozone levels? Atmospheric Chemistry Physics 6, 51-66.

Kalthoff, N., Kottmeier, C., Thürauf, J., Corsmeier, U., Saïd, F., Fréjafon, E., Perros, P.E., 2005. Mesoscale circulation systems and ozone concentrations during ESCOMPTE: a case study from IOP 2b. Atmospheric Research 74 (1-4), 355-380.

Knowlton, K., et al., 2004. Assessing ozone-related health impacts under changing climate. Environmental Health Perspectives 112, 1557-1563.

Langner, L., Bergström, R., Foltescu, V., 2005. Impact of climate change on surface ozone and deposition of sulphur and nitrogen in Europe. Atmospheric Environment 39 (6), 1129-1141.

Liakakou, E., Vrekoussis, M., Bonsang, B., Donousis, Ch., Kanakidou, M., Mihalopoulos, N., 2007. Isoprene above the Eastern Mediterranean: seasonal variation and contribution to the oxidation capacity of the atmosphere. Atmospheric Environment 41, 1002-1010. 
Meehl, G.A., Tebaldi, C., 2004. More Intense, More Frequent, and Longer Lasting Heat Waves in the 21st Century. Science 305, 994-997.

Moukhtar, S., Bessagnet, B., Rouil, L., Simon, V., 2005. Monoterpene emissions from Beech (Fagus sylvatica) in a French forest and impact on secondary pollutants formation at regional scale. Atmospheric Environment 39, 3535-3547.

Pal, J.S., Giorgi, F., Bi, X., 2004. Consistency of recent European summer precipitation trends and extremes with future regional climate projections. Geophysical Research Letters 31, L13202.

Parodi, S., Vercelli, M., Garrone, E., Fontana, V., Izzotti, A., 2005. Ozone air pollution and daily mortality in Genoa, Italy between 1993 and 1996. Public Health 119 (9), 844-850.

Scebba, F., Giuntini, D., Castagna, A., Soldatini, G., Ranieri, A., 2005. Analysing the impact of ozone on biochemical and physiological variables in plant species belonging to natural ecosystems. Environmental and Experimental Botany 235-246.

Schar, C., Vidale, P.L., Frei, C., Luthi, D., Haberli, C., Liniger, M.A., Appenzeller, C., 2004. The role of increasing temperature variability in European summer heat waves. Nature 427, 332-336.

Schlink, U., Herbarth, O., Richter, M., Dorling, S., Nunnari, G., Cawley, G., Pelikan, E., 2006. Statistical models to assess the health effects and to forecast ground-level ozone. Environmental Modelling \& Software 21 (4), 547-558.

Schmidt, H., Derognat, C., Vautard, R., Beekmann, M., 2001. A comparison of simulated and observed ozone mixing ratios for the summer of 1998 in western Europe. Atmospheric Environment 35 (36), 6277-6297.

Seth, A., Rojas, M., 2003. Simulation and sensitivity in a nested modeling system for South America. Part I: reanalyses boundary forcing. Journal of Climate 16, 2437-2453.

Sillman, S., 2000. Ozone production efficiency and loss of NOx in power plant plumes: photochemical model and interpretation of measurements in Tennessee. Journal of Geophysical Research 105 (D7), 9189-9202.

Simpson, D., 1999. Inventorying emissions from nature in Europe. Journal of Geophysical Research 104, 8113-8152.
Small, E.E., Giorgi, F., Sloan, L.C., 1999. Regional climate model simulation of precipitation in Central Asia: mean and interannual variability. Journal of Geophysical Research 104, 6563-6582.

Steiner, A.L., Tonse, S., Cohen, R.C., Goldstein, A.H., Harvey, R.A., 2006. , Influence of future climate and emissions on regional air quality in California. Journal of Geophysical Research 111, D18303.

Stedman, J.R., 2005. The predicted number of air pollution related deaths in the UK during the August 2003 heatwave. Atmospheric Environment 38 (8), 1087-1090.

Stevenson, D., Doherty, R., Sanderson, M., Johnson, C., Collins, B., Derwent, D., 2005. Impacts of climate change and variability on tropospheric ozone and its precursors. Faraday Discussion 130, 41.

Sun, L., Semazzi, F.H.M., Giorgi, F., Ogallo, L., 1999. Application of the NCAR regional climate model to eastern Africa. Part II: simulation of interannual variability of the short rains. Journal of Geophysical Research 104, 6549-6565.

Szopa, S., Hauglustaine, D., Vautard, R., Menut, L., 2006. Evolution of the tropospheric composition in 2030: impact on European air quality. Geophysical Research Letter 33, L14805.

Vautard, R., Honoré, C., Beekmann, M., Rouil, L., 2005. Simulation of ozone during the August 2003 heat wave and emission control scenarios. Atmospheric Environment 39 (16), 2957-2967.

Vautard, R., Szopa, S., Beekmann, M., Menut, L., Hauglustaine, D.A., Rouil, L., Roemer, M., 2006. Are decadal anthropogenic emission reductions in Europe consistent with surface ozone observations? Geophysical Research Letters 33, L13810.

Vestreng, R., 2003. Emission data reported to CLRTAP. EMEP MSC-W Status Report 2003. Technical Report Note 1/2003, Meteorological Synthesizing Centre, West, Norwegian Meteorological Institute, Oslo, Norway.

von Kuhlmann, R., Lawrence, M.G., Poschl, U., Crutzen, P.J., 2004. Sensitivities in global scale modeling of isoprene. Atmospheric Chemistry Physics 4, 1-17. 